We are very much indebted to Dr. K. Bailey for the specimen of tropomyosin, and to Dr. G. R. Tristram for the specimen of silk fibroin.

'Woodward, R. B., and Schramm, C. H., J. Amer. Chem. Soc., 69, 1551 (1947).

${ }^{2}$ Leuchs et al., Ber., 29, 857 (1906); 40, 3235 (1907); 41, 1721 (1908),

- Meyer, K. H., and Go, Y., Helv. Chim. Acta, 17, 1488 (1934).

- Baldwin, A. W., Barr, T., and Speakman, J. B., J. Soc. Dyers and Colourists, 62, 4 (1946).

Bunn, C. W., and Garner, E. V., Proc. Roy. Soc., A, 189, 39 (1947).

${ }^{6}$ Corey, R. B., Chem. Rev., 26, 227 (1940).

'Brown, C. J., Coleman, D., and Farthing, A. C. (in the press).

${ }^{-}$See, for example, Astbury, W. T., Croonian Lecture, 1945, Proc. Roy. Soc., B, 134, 303 '(1947); also many communications to Nature.

- Astbury, W. T., and Bell, F. O., Nature, 147, 696 (1941).

10 Darmon, S. E., and Sutherland, G. B. B. M., J. Amer. Chem. Soc., 69, $2074(1947)$

1 Astbury, W. T., Reed, R., and Spark, I. C., Biochem. J. (in the press).

\section{COLOUR AND COLOUR VISION IN ANIMALS}

$\mathrm{O}$ September 13, a series of papers on colour and colour vision in animals was read before Section D (Zoology) of the British Association. The object of the discussion was to consider recent results on the physiology of colour production and appreciation in animals, and the bearings of these results on theories of the biological uses of colour-in protective resemblance, mimicry, warning coloration and other ways.

The discussion was opened by Dr. R. J. Pumphrey with a paper on the distribution of colour perception in the animal kingdom. He first pointed out the difficulties in the way of obtaining experimental proof of the presence of colour discrimination in animals, which can tell us of their perceptions only by their behaviour. Besides this, colour is itself a difficult experimental subject; it is never easy to exclude other stimuli such as those of variations in brightness-to the animal and not to us-and, if the animal's spectral range differs from ours, control of wave-lengths outside our visible range is needed. Further, the animal's behaviour will be influenced only if perception of the colour is important to it ; and changes of behaviour can be interpreted only if the animal behaves in a consistent and intelligible manner, and is not disturbed by other stimuli or by its own nervous state.

Nevertheless, colour perception has been established beyond reasonable doubt in some insects and, among vertebrates, in some bony fishes, reptiles, birds and the primates. Dr. Pumphrey believes its presence in the Crustacea and Cephalopoda unproved. In the rest of the animal kingdom there is no sound evidence of its presence, and in many groups failure to demonstrate it makes its presence unlikely.

Animal colour perception, where it exists, resembles our own rather closely. There is no evidence of dichromatism as a primitive condition; but this may be due to inadequate experimental methods. Some birds and fishes may have a closed colour circle, that is, they may fail to distinguish red from violet, and may not recognize extra-spectral purples. Many insects see much farther into the ultra-violet than we do, and can distinguish ultra-violet from the parts of the spectrum visible to us. Insects see colours in weak light so long as they are able to see at all; in this they are in contrast with vertebrates, whose perception of colour fails in weak light. At night vertebrates have no colour sense; all nocturnal vertebrates are colour-blind.

Dr. R. W. Pickford spoke on the varieties of colour vision in man. Total colour-blindness is rare. The most usual abnormalities are deuteranopia, in which red and green are confused, looking yellowish, and protanopia, in which there is also a great darkening of the red end of the spectrum. In anomalous colour vision, discrimination of colours is retained; but either red or green may be greatly weakened as compared with the normal. With red anomalous vision there is in some cases also darkening of the red end of the spectrum. All are Mendelian recessives and sex-linked, except that in total colour-blindness the linkage is partial. About 7 per cent of men show red-green colour-blindness.

In addition to these major defects, minor variations from normality occur. The commonest is a weakness of blue discrimination ; those with it tend to confuse greenish-blues, such as Cambridge blue, with green. Yellow weakness also occurs, and leads to confusion of yellow with white. These minor defects are not sex-linked.

Dr. M. G. M. Pryor discussed the conditions under which colour in an animal can be certainly said to be adaptive. Adaptiveness implies that the colour has selective value and that in the absence of selection the colour would be different from what it now is. To prove adaptiveness, we therefore need to know the natural non-adaptive colour. Often this is white, as in many cave animals that live in the dark, but not always so. Some cave insects are black or brown, the colour of the dark tannin with which their chitin is hardened. Dark colour in an insect therefore needs no 'adaptive' explanation. Whiteness in an insect is more unusual and is often due to a layer of unhardenedand undarkened-chitin outside the dark chitin within it.

Brilliant colours are not always adaptive. Golden colour, as in the pupa of the peacock butterfly, may be due to the natural colour of the chitin. Brilliant interference colours may be due to a number of thin, transparent films of chitin of the right thickness. Often these colours occur where they cannot be adaptive-inside the cast skins of bluebottle pupæ, or in the bristles of the sea-mouse which lives buried in mud. The blues and greens of the outer surface of bluebottles and dung-flies are due to interference at the layer of wax that covers tne chitin.

Some of these colours may have been exaggerated or otherwise modified adaptively, but a knowledge of what the colours would be without adaptation and of the manner in which they are produced is necessary if we are to assess the adaptive element in them.

Dr. G. S. Carter discussed, in the light of the facts given by the previous speakers, the conditions under which colour as seen by other animals may be of importance in the biology of an animal. First, it is clear that not all animal colour has this importance. To the categories of non-significant colour already mentioned may be added much colour in lower in. vertebrates, such as many sea-anemones and seaurchins, which have few enemies. This is at least true of the many species that do not catch large animals as prey. Much colour in physiological sub. stances is non-significant-blood pigments, excretory substances. Some pigment may be used as defence against light, as probably the black pigment of many 
desert animals, but is not related to the animal's contacts with other animals.

Value in colour in the biological environment implies that the animal seeing it has colour vision. As Dr. Pumphrey showed, only some arthropods and some vertebrates have been shown experimentally to have this faculty. Perhaps some cephalopods should be added, on the evidence of their natural behaviour and not on experimental results. Such evidence may be as conclusive as the experimental.

Wherever colour is of value in the interactions of animals, except in the rare cases where the stimulus is a simple flash of colour, pattern appreciation as well as colour perception is necessary in the observing animal. It is therefore not surprising that a colour sense and an image-forming $\theta y \Theta$ are associated in animals, for pattern appreciation is the characteristic of image-forming eyes.

In recognition of an animal by another, two distinct components of the process of recognition must be distinguished. First, the animal must be recognized as a discrete object on its background. This is prevented by the various forms of camouflage. Secondly, the animal must be recognized as of a particular kind-for example, of a kind suitable as food. To understand how the second can be prevented by adaptation in colour and pattern, we need to know how animals recognize the kinds of objects.

In much of their behaviour, animals, even such complex animals as birds and insects, recognize the kinds of objects not by an aggregate of many characters, as we do, but by one, or at most a few, 'valent' characters, such as the smell, shape, colour, pattern or type of movement. Not all animal behaviour is of this simple type; but so far as it is a resemblance that includes the valent characters will be effective, although in other characters there is no resemblance. But if an animal is exposed to predators of many species, a detailed and complicated resemblance may be built up by combining the different valent characters required by the various species. We can thus see how the astonishingly accurate resemblances we find in Nature may have originated from very partial resemblances which, in spite of their incompleteness, would still have had some value.

G. S. CARTER

\section{PHYSIOLOGY OF LACTATION}

A T a joint meeting of Sections M (Agriculture) and I (Physiology) of the British Association, held at Brighton on September 14, recent research on the physiology of lactation was discussed. Prof. $H$. Hartridge, president of Section I, was in the chair. The discussion was introduced by Prof. H. D. Kay (National Institute for Research in Dairying, Shinfield) who said that in view of the importance of lactation both from the human and from the industrial points of view, it is remarkable that the physiology of the mammary gland had, until recent years, received so little attention. During the past dozen years, however, knowledge has advanced substantially as regards the endocrine control of mammary development and of milk secretion, including the artificial induction of lactation in the virgin or barren animal, the hormonal inhibition of lactation, the cytology of the gland in relation to function and the 'let-down' of milk as a conditioned neuro-hormonal reflex. The biochemistry of milk secretion, including both glandular metabolism and the factors affecting milk composition, have also undergone active study. Advances in knowledge of the neuro-hormonal mechanisms by which the mammary gland is controlled are already beginning to influence both milking technique and also clinical methods of dealing with problems of human lactation.

There is a very rapid blood-flow through the actively secreting gland, and a large consumption of oxygen. The respiratory quotient of the secreting tissue is, in the intact animal, well above unity, and in surviving slices of tissue suspended in a nutrient solution, figures as high as $1 \cdot 5-1 \cdot 6$ have been obtained by $\mathrm{T}$. $\mathbf{H}$. French, suggesting fat formation from carbohydrate. A major difficulty in recent biochemical studies in the intact animal is the uncertainty of the extent of error due to lymph drainage, and all findings depending on arterio-venous changes must be interpreted very cautiously.

The practical significance was pointed out of the recent work of Dodd and Foot at Shinfield, who have found that more than 50 per cent of the fat originally present in the secreted milk in the bovine udder is not removed during the ordinary process of milking. Very recent findings which indicated that milk composition might be influenced by naturally occurring cestrogens present in young grass and clover were also described. The relationship between the texture of the teat and liability to udder infection, established in the last few months by J. I. Taylor at Compton, was mentioned as a new factor that seems of importance in buying or breeding a cow.

Mr. K. C. Richardson (University College, London) described with the aid of slides some of the results of his recent studies of the cytology of the mammary gland in relation to function. The milk-secreting alveoli are not usually spherical, but are rather elongated structures, the secreting cells of which show great changes in shape and size at different stages in the secretory cycle. The synthesized milk constituents pass from these cells into the alveolar lumen by recurrent rupture of the cell membrane. Whether or not there are nerve fibres ending in the secretory tissue is as yet unsettled, the available histological technique being insufficiently specific. $\mathrm{He}$ discussed the possible mechanism of 'let-down'. There is no doubt that during 'let-down' active pressure is brought to bear on the milk which has been secreted into the alveoli. Smooth muscle, though present in the mammary gland, is neither in the right places nor in sufficient quantity to make any serious contribution to the 'let-down' phenomenon. There are no sphincters on the ducts emerging from the lobules. However, as a result of a recent advance in histological technique, clear evidence has been obtained of the abundant presence in the gland of myo-epithelial cells, the large nuclei of which are usually to be found between the alveolar secreting cells and the basement membrane, and the processes of which can be shown to extend over the outer surface of each alveolus. Convincing histological evidence was brought forward by $\mathbf{M r}$. Richardson that these cells can and do contract at 'let-down'; the basket structure, tightly embracing the distended alveolus before 'let-down', does not become flaccid when the milk has been forced out and the alveolus diminished in size, but remains taut.

Dr. S. J. Folley (National Institute for Research in D.xirying, Shinfield) briefly mentioned three stages 